tion both at home and abroad, for take it all in all, as Mr. Bullen says, "no catalogue in the world, whether in print or in manuscript, is equal to that of the British Museum." We hope, therefore, that the proposal of the Society will speedily meet with a favourable response from Govern-

\title{
A MIRROR BAROMETER
}

M. LÉON TEISSERENC DE BORT has invented an aneroid mirror barometer, which is described in a recent number of La Nature. It is based on a method analogous to that well-known since the researches of Gauss for the reading of small rotations. $M$. Teisserenc de Bort has sought to obtain an aneroid barometer which will give precise observations at sea, especially in rough weather, when it is impossible to read the mercury barometer. The principle of this barometer is very simple. The elastic tub or box B carries, as in most aneroids, a metallic point, which follows its movements. In the precise.

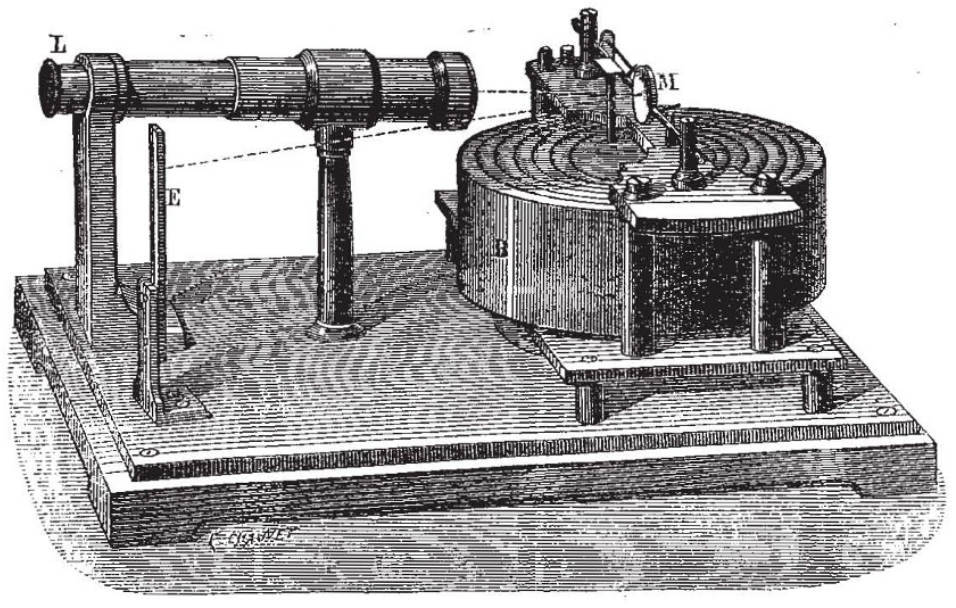

Teisserenc de Bort's mirror barometer.

As to the amplification of the movements necessary to enable us to appreciate millimetres and their fractions, this is obtained by reading with i he aid of a small reticled telescope, $\mathrm{L}$, the image of a rraduated scale $\mathrm{E}$ which is reflected in the mirror M. By combining the enlargement of the telescope with th distance of the scale from the mirror, we succeed in giving to the apparatus a length of less than $20 \mathrm{~cm}$. by $\mathrm{I} 2$, which renders it quite portable. It is important to remark that the amplification of the movements of the box, which, in ordinary barometers, is obtained by means of several levers, is obtained here by an optical process; it follows that the numerous frictions and the time lost in contacts are mostly ment, and that should it be decided to print the British Museum Catalogue, some plan will be formed by which proofs may be revised not only by qualified bibliographers, but that the various departments of literature, science, and art will be represented on the staff of revisers.

ordinary aneroid the transformation of the vertical move ment into a rotating movement necessitates either a chain or a curb, or a sort of fork which works in a spiral furrow cut in the axis which supports the needle. These various systems have the inconvenience of producing frictions some of them are liable to dust and rust. In the mirror barometer, the transformation of the movement is obtained by the simple contact of a small palette supported on the axis of the mirror and of the point spoken of above. As the angle which the plane of the mirror may describe does not exceed $12^{\circ}$ on each side of the vertical, it follows that the contact of the point in the palette is always

\section{BUTTERFLIES WITH DISSIMILAR SEXES}

NATURALISTS have long been familiar with the fact that the two sexes of certain species of lepidoptera often differed from each other in colour and marking, and sometimes in form and size to a very considerable extent. For this phenomenon the convenient term "Antigeny" has been proposed by Mr. S. H. Scudder. In accordance with Darwin's theory of sexual selection we find that when the sexes of a butterfly differ to any marked extent in colour, it is generally the male which is the more gaudily coloured, although there are certain genera in which the reverse obtains; but, as I pointed out in NATURE (vol. iii. p. 508), there is reason to believe that in these exceptional cases the males may be

$$
\text { x Proc. Amer. Acad., xii. } x_{50} \text {. }
$$

eliminated. There remains only a single movement, that of the axis which bears the mirror; in the barometer figured the pivots are of steel and the cap of platinum, and in order to avoid rust, the whole is nickel-plated.

M. Teisserenc de Bort proposes to construct others, in which the axis will be mounted on rubies. This garniture will not sensibly increase the price of the apparatus. This instrument is too new to allow us to appreciate the full degree of precision which it can attain. In a trial in a captive balloon by Capt. Perrier of several aneroids as compared with the mirror, the latter showed a great sensibility, and it quickly resumed its original position on landing.

the selecting sex. Mr. Charles Darwin having recently called my attention to a paper on this subject in Kosmos, by that most philosophical entomologist, Fritz Müller, I have thought that an abstract might interest readers of NATURE.

The species of which the author treats, Epicalia acontius, has such very dissimilar sexes that Fabricius described them as distinct species, calling the male Antiochus and the female Medea, while in Doubleday and Westwood's "Genera of Diurnal Lepidoptera" the two sexes are placed in different genera, the male in Epicalia and the female in Myscelia. It is not known with certainty who first pointed out that Antiochus and Medea were the sexes of the same species; but this fact is now I "Epicalia acontius. Ein ungleiches Ehepaar," Kosmos, January, 1879 , p. 285 . 